Check for updates

Cite this: Chem. Sci., 2018, 9, 8982

๑ All publication charges for this article have been paid for by the Royal Society of Chemistry

\title{
Molybdenum sulfide-reduced graphene oxide $p-n$ heterojunction nanosheets with anchored oxygen generating manganese dioxide nanoparticles for enhanced photodynamic therapy $\dagger$
}

\begin{abstract}
Sutanu Kapri and Sayan Bhattacharyya (iD *
In an unprecedented approach, $\mathrm{p}-\mathrm{n}$ heterojunction nanosheets comprising $\sim 5 \mathrm{~nm}$ thick $\mathrm{p}$-type $\mathrm{MoS}_{2}$ nanoplates integrated onto $n$-type nitrogen doped reduced graphene oxide ( $n$-rGO) have been employed for photodynamic therapy (PDT). When near infrared (NIR) light with $980 \mathrm{~nm}$ wavelength was irradiated on this nanocomposite, effective electron-hole separation was obtained across the heterojunction. The nanosheets were modified with lipoic acid functionalized poly(ethylene glycol) to provide better biocompatibility and colloidal stability in physiological solution. The surface decorated 3-5 nm $\mathrm{MnO}_{2}$ nanoparticles (NPs) triggered the disproportionation of intracellular $\mathrm{H}_{2} \mathrm{O}_{2}$ which improved generation of reactive oxygen species (ROS) for enhanced PDT cancer therapy, studied in vitro. The role of $\mathrm{N}$-doping in $\mathrm{rGO}$ and the effect of immobilization of $\mathrm{MnO}_{2} \mathrm{NPs}$ were systematically investigated by control experiments. Our smartly designed $\mathrm{p}-\mathrm{MoS}_{2} / \mathrm{n}-\mathrm{rGO}-\mathrm{MnO}_{2}-\mathrm{PEG}$ nanosheets outperform conventional PDT agents by overcoming limitations such as low absorption band, unfavourable bioavailability and limitations in tissue oxygenation.
\end{abstract}

Received 7th June 2018

Accepted 29th September 2018

DOI: $10.1039 / \mathrm{c} 8 \mathrm{sc} 02508 \mathrm{~h}$

rsc.li/chemical-science

\section{Introduction}

The p-n heterojunction between semiconductor materials of dissimilar band gaps can be used to engineer the electronic energy bands and therefore provide real time control over the electronic conductivity across graded or abrupt interfaces. ${ }^{1}$ Apart from electronic and optoelectronic device applications ranging from transistors ${ }^{2}$ and solar cells ${ }^{3}$ to lasers, ${ }^{4}$ where the $\mathrm{p}-\mathrm{n}$ junction acts as the basic building block, the unorthodox use of heterostructures consisting of multiple heterojunctions is highly intriguing whereby the separated charge carriers can be utilized for chemical and biochemical transformations. For instance NIR light absorbing $\mathrm{p}-\mathrm{n}$ heterostructures can be employed in PDT with the advantages of minimal side effect. ${ }^{5}$ In general PDT employs NIR light with far more penetration depth inside soft biological tissues than UV/visible light, where the photosensitizer subsequently transfers its energy to molecular oxygen to create ROS for selective destruction of key cellular components via apoptosis and necrosis mediated pathways. ${ }^{6,7}$

Department of Chemical Sciences, Centre for Advanced Functional Materials, Indian Institute of Science Education and Research (IISER) Kolkata, Mohanpur - 741246, India.E-mail: sayanb@iiserkol.ac.in

$\uparrow$ Electronic supplementary information (ESI) available: Experimental section; FESEM, AFM and TEM images; $\mathrm{N}_{2}$ sorption isotherms; Mott-Schottky plots; FTIR spectra; zeta potential; fluorescence spectra; cell viabilities; photothermal heating curves; comparison of fluorescence intensities; and live-dead cell assay. See DOI: $10.1039 / \mathrm{c} 8 \mathrm{sc} 02508 \mathrm{~h}$
In the case of the $\mathrm{p}-\mathrm{n}$ heterojunction, the excited electrons in the conduction band can react with $\mathrm{O}_{2}$ to form superoxide anion radicals $\left(\mathrm{O}_{2}^{-\cdot}\right)$ and holes in the valence band can react with $\mathrm{H}_{2} \mathrm{O}$ to form hydroxyl radicals, ${ }^{8}$ both of which are extremely cytotoxic towards cancer cells. Recently Au-CuS heterojunction NPs have been employed to produce cytotoxic ROS, ${ }^{9}$ and $\mathrm{BiOI} @ \mathrm{Bi}_{2} \mathrm{~S}_{3} @$ bovine serum albumin heterojunction NPs were reported as radio/photo-sensitizers for cancer therapy. ${ }^{10}$ Although Tian, Bezanilla and co-workers have demonstrated free-standing coaxial p-type/intrinsic/n-type silicon nanowires in neuromodulation via a photoelectrochemical process, ${ }^{11}$ to the best of our knowledge, the strategy of employing a nanoscale $\mathrm{p}-\mathrm{n}$ heterojunction in photodynamic cancer therapy has not been explored. In the past, n-type nitrogen doped reduced graphene oxide (n-rGO) supported p-type $\mathrm{MoS}_{2}$ nanoplates have been used in photochemical/photoelectrochemical hydrogen generation. ${ }^{8}$ This particular system has remarkable potential in PDT; however their large size restricts the intended biomedical applications. Moreover, the development of a photosensitizing nanosystem that can alleviate tumour hypoxia is extremely challenging.

We use the $\mathrm{p}-\mathrm{n}$ heterojunction concept to develop a PDT agent consisting of poly(ethylene glycol) modified (PEGylated), $\mathrm{MnO}_{2} \mathrm{NP}$ decorated $\mathrm{p}-\mathrm{MoS}_{2} / \mathrm{n}$-rGO nanosheets $\left(\mathrm{p}-\mathrm{MoS}_{2} / \mathrm{n}-\mathrm{rGO}-\right.$ $\mathrm{MnO}_{2}-\mathrm{PEG}$ ). The nanosheet structure has the advantages of a large surface area and rapid absorption of NIR light. ${ }^{12}$ While the coordination of a semiconductor like $\mathrm{p}-\mathrm{MoS}_{2}$ on $\mathrm{n}$-rGO 
improves photogeneration of electron-hole pairs, ${ }^{\mathbf{8 , 1 3}}$ the heterojunction promotes the migration of electrons and holes, and enhances the separation of charge carriers upon NIR light irradiation. The role of $\mathrm{MnO}_{2}$ is to overcome the hypoxic conditions prevalent within the tumour microenvironment, by generating $\mathrm{O}_{2}$ in the presence of a high level of $\mathrm{H}_{2} \mathrm{O}_{2}(100 \mu \mathrm{M}$ to $1 \mathrm{mM}$ ) via the Fenton reaction. ${ }^{\mathbf{1 4 - 1 7}}$ In vitro studies clearly demonstrate the PDT efficacy of this nanosystem that can overcome the basic limitations of common photosensitizers such as absorption of light in the UV-visible region, low photostability, low cellular uptake, non-uniform distribution within cancerous tissues, poor hydrophilicity and poor resistance to enzymatic degradation. ${ }^{18}$ ROS generation within the tumour tissues could be controllably achieved by this $\mathrm{O}_{2}$ self-sufficient nanoplatform under $980 \mathrm{~nm}$ NIR irradiation at $0.4 \mathrm{~W} \mathrm{~cm}-2$ power density.

\section{Results and discussion}

The top panel in Scheme 1 shows the synthesis methodology of p- $\mathrm{MoS}_{2} /$ n-rGO- $\mathrm{MnO}_{2}-\mathrm{PEG}$ heterojunction nanosheets through liquid exfoliation of $\mathrm{GO}$ and hydrothermal reaction with $\mathrm{Na}_{2}$ $\mathrm{MoO}_{4} \cdot 2 \mathrm{H}_{2} \mathrm{O}$ and thiourea, followed by nitrogen doping and subsequent anchoring of $\mathrm{MnO}_{2}$ NPs. Herein thiourea not only acts as a source of sulphur to form $\mathrm{MoS}_{2}$ but also acts as a reducing agent for GO to rGO conversion (see the Experimental section, ESI $\dagger$ ). In the fourth step, lipoic acid termination of PEG (LA-PEG 2000 ) provides better biocompatibility and colloidal stability in physiological solution (Fig. S1†). ${ }^{19}$ The lower panel of Scheme 1 shows the conceptual basis of this work whereby the PEGylated $\mathrm{p}-\mathrm{n}$ heterojunction nanosheets serve as an NIR light triggered photosensitizer equipped with the capability to separate electrons and holes. Once the surface modulated nanosheets are internalized within the blood vessel and accumulated at the tumour area, endogenous $\mathrm{H}_{2} \mathrm{O}_{2}$ influenced and $\mathrm{MnO}_{2} \mathrm{NP}$ triggered $\mathrm{O}_{2}$ generation is balanced by its transformation into cytotoxic ROS components such as hydroxyl radicals $(\cdot \mathrm{OH})$ and singlet oxygen $\left({ }^{1} \mathrm{O}_{2}\right)$ by the separated charge carriers, analogous to photocatalytic water splitting.

In order to understand the relevance of each component in the designed PDT agent, three PDT nanosystems were studied, (i) $\mathrm{MoS}_{2} /$ rGO-PEG nanosheets, where $\mathrm{MoS}_{2}$ nanoplates are grown in situ on undoped rGO, (ii) $\mathrm{p}-\mathrm{MoS}_{2} / \mathrm{n}$-rGO-PEG nanosheets, where p-type $\mathrm{MoS}_{2}$ nanoplates are grown in situ on nitrogen doped n-rGO, and finally (iii) p- $\mathrm{MoS}_{2} / \mathrm{n}-\mathrm{rGO}-\mathrm{MnO}_{2}-$ PEG, where $\mathrm{MnO}_{2}$ NPs are decorated onto p-MoS $/$ n-rGO heterojunction nanosheets. Exfoliation of GO nanosheets reduces its average length and thickness from $\sim 500 \mathrm{~nm}$ and $5 \mathrm{~nm}$ for the as-synthesized free-standing GO to $\sim 170 \mathrm{~nm}$ and $\sim 2.8 \mathrm{~nm}$ for the exfoliated GO nanosheets, respectively (Fig. S2 $\dagger$ ). While nitrogen doping in rGO does not significantly alter the above dimensions, the rGO/n-rGO nanosheets suppress the aggregation of $\mathrm{MoS}_{2}$ nanoplates which otherwise aggregate in flowerlike clusters (Fig. S2†). Similarly Fig. 1a shows that the p$\mathrm{MoS}_{2} / \mathrm{n}$-rGO-PEG nanosheets have a mean lateral dimension of $\sim 180 \mathrm{~nm}$, along with 5-12 nm long strips of $\mathrm{p}-\mathrm{MoS}_{2}$ nanoplates grown on n-rGO, as seen from the lattice fringes in Fig. S2h. $\dagger$ The crystalline $\mathrm{p}-\mathrm{MoS}_{2}$ nanoplates with an interplanar spacing of $0.62 \mathrm{~nm}$ grow in the [002] direction (Fig. 1b). 3-5 nm diameter $\mathrm{MnO}_{2}$ NPs are immobilized on n-rGO through electrostatic interaction between the positively charged $\mathrm{Mn}^{2+}$ ions and negatively charged oxygen containing functional groups present on the rGO surface (Fig. 1c and d). The interplanar spacing of crystalline $\mathrm{MnO}_{2}$ is $0.23 \mathrm{~nm}$ corresponding to the (211) reflection, consistent with bare $\mathrm{MnO}_{2}$ NPs (Fig. S2 $\dagger$ ). ${ }^{20}$ Moreover, the

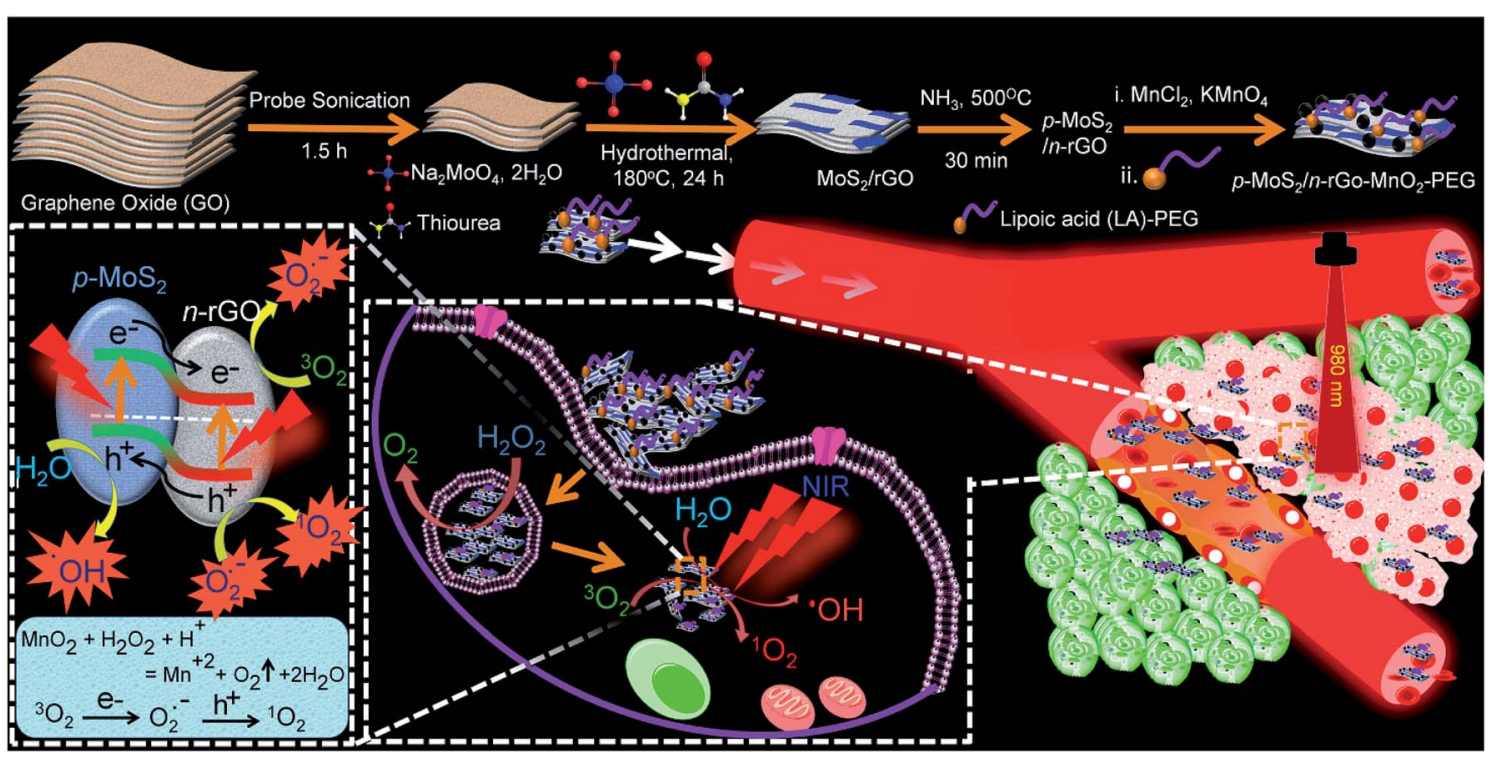

Scheme 1 Schematic illustration of the fabrication of $\mathrm{p}-\mathrm{MoS}_{2} / \mathrm{n}-\mathrm{rGO}-\mathrm{MnO}_{2}-\mathrm{PEG}$ nanosheets. While the hybrid nanosheets generate ROS via electron-hole separation under $980 \mathrm{~nm}$ laser irradiation, the $\mathrm{MnO}_{2} \mathrm{NPs}$ trigger the decomposition of endogenous $\mathrm{H}_{2} \mathrm{O}_{2}$ into $\mathrm{O}_{2}$, simultaneously enhancing the PDT effect. 

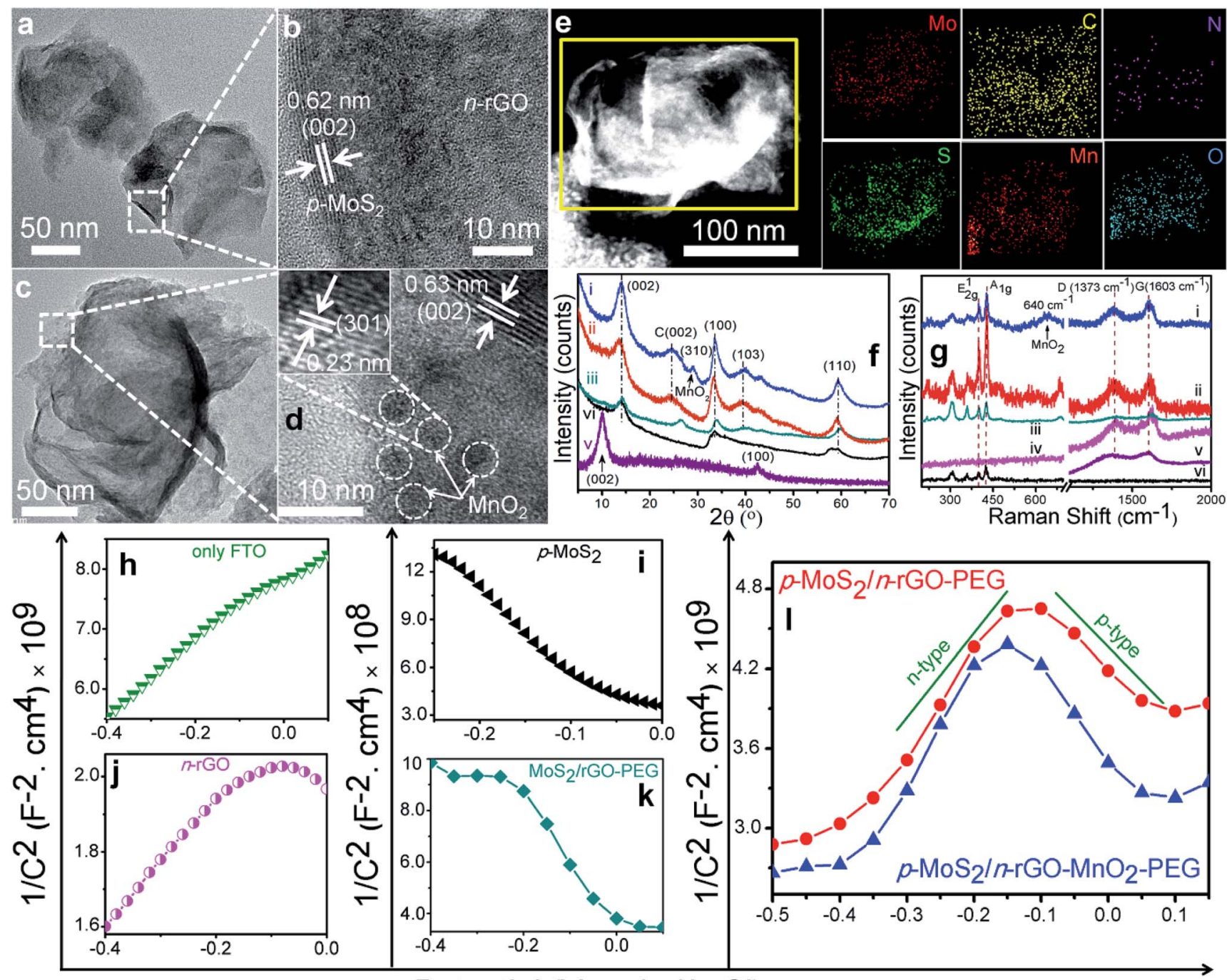

Potential (V vs Ag/AgCl)

Fig. 1 ( $a$ and $c$ ) Low and ( $b$ and d) high magnification TEM images of $p-M_{0} S_{2} / n-r G O-P E G$ and $p-M o S_{2} / n-r G O-M n O_{2}-P E G$, respectively. The insets of (d) show the interlayer spacing of $\mathrm{MoS}_{2}$ nanoplates and $\mathrm{MnO}_{2} \mathrm{NPs}$. (e) HAADF-STEM image of $\mathrm{p}-\mathrm{MoS} 2 / \mathrm{n}-\mathrm{rGO}-\mathrm{MnO} \mathrm{O}_{2}-\mathrm{PEG}$ and the corresponding maps showing the elemental distribution of $M o, S, C, M n, N$ and O. (f) XRD patterns and (g) Raman spectra of (i) p-MoS $/ 2$-rGO$\mathrm{MnO}_{2}-\mathrm{PEG}$, (ii) $\mathrm{p}-\mathrm{MoS}_{2} / \mathrm{n}-\mathrm{rGO}-\mathrm{PEG}$, (iii) $\mathrm{MoS}_{2} / \mathrm{rGO}-\mathrm{PEG}$, (iv) n-rGO, (v) GO and (vi) $\mathrm{MoS}_{2}$. Mott-Schottky plots of (h) the bare FTO glass substrate, (i) p-type $\mathrm{MoS}_{2}$, (j) n-rGO, (k) $\mathrm{MoS}_{2} / \mathrm{rGO}-\mathrm{PEG}$ and (l) $\mathrm{p}-\mathrm{MoS}_{2} / \mathrm{n}$-rGO-PEG and p-MoS $/ \mathrm{n}-\mathrm{rGO}-\mathrm{MnO} \mathrm{O}_{2}-\mathrm{PEG}$

uniform elemental distribution over the nanosheets attests to the successful design of $\mathrm{p}-\mathrm{MoS}_{2} / \mathrm{n}$-rGO-MnO ${ }_{2}-\mathrm{PEG}$ (Fig. 1e). While the atomic ratio of Mo: $\mathrm{S}$ is $4: 9.4$ in $\mathrm{p}-\mathrm{MoS}_{2}$, the nearly equivalent weight fraction of $\mathrm{C}$ and Mo (Table $\mathrm{S} 1 \dagger$ ) shows a uniform distribution of the $\mathrm{p}-\mathrm{MoS}_{2}$ nanoplates on n-rGO with $\sim 8.7 \mathrm{wt} \% \mathrm{~N}$. The desired nanosheets retain their average lateral dimension of $\sim 190 \mathrm{~nm}$ and thickness of 5-6 $\mathrm{nm}$ while retaining high monodispersity (Fig. S3†), suitable for cellular internalization. The nanosheets possess a decent surface area and the pore size distribution is between 3 and $3.6 \mathrm{~nm}$ (Fig. S4†). For instance the specific surface area increases from $94 \pm 4$ to $106 \pm$ $3 \mathrm{~m}^{2} \mathrm{~g}^{-1}$ after nitrogen doping and decreases to $55 \pm 2 \mathrm{~m}^{2} \mathrm{~g}^{-1}$ after $\mathrm{MnO}_{2} \mathrm{NP}$ incorporation (Table $\mathrm{S} 2 \dagger$ ). The mesoporous nature, showing capillary condensation, ${ }^{21}$ provides active catalytic sites, enhancing their photocatalytic performance. Fourier transform infrared (FTIR) spectral analysis (Fig. S5†) and zeta potential measurements (Fig. S6 $\dagger$ ) suggest the presence of graphitic domains of $\mathrm{rGO}^{22}$ and efficient grafting and conjugation of lipoic acid and PEG onto the nanosheets.

Structural information on the nanosheets at different stages was obtained from powder X-ray diffraction (PXRD; Fig. 1f) and Raman spectral analysis (Fig. 1g). Both the bare and GO immobilized $\mathrm{MoS}_{2}$ crystallize in the hexagonal phase (JCPDS card no. 37-1492). The successful conversion of GO to rGO by thiourea is evident from the shift of the (002) reflection from $2 \theta=10^{\circ}$ to $24.6^{\circ}$, respectively. ${ }^{23}$ In $\mathrm{p}-\mathrm{MoS}_{2} / \mathrm{n}-\mathrm{rGO}-\mathrm{MnO}_{2}-\mathrm{PEG}$, $\mathrm{MnO}_{2}$ can be distinguished from $\mathrm{MoS}_{2}$ by its distinct (310) reflection at $2 \theta=29^{\circ} .{ }^{24}$ Similarly in the Raman spectra, the $640 \mathrm{~cm}^{-1}$ vibrational band of $\mathrm{MnO}_{2}$ is prominent within the characteristic bands of $\mathrm{MoS}_{2}$ at 377 and $403 \mathrm{~cm}^{-1}$ for in-plane $\mathrm{E}_{1 \mathrm{~g}}$ and out-of-plane $\mathrm{A}_{1 \mathrm{~g}}$ vibration modes, respectively. ${ }^{25}$ In rGO, the $\mathrm{sp}^{2}$ graphitic (G) band at $1603 \mathrm{~cm}^{-1}$ is more intense 
than the disordered (D) band at $1373 \mathrm{~cm}^{-1}$ facilitating a conducting channel for movement of charge carriers. ${ }^{26}$ To investigate the semiconducting nature, the nanosheets were deposited on fluorine doped tin oxide (FTO) glass substrates (see the Experimental section for details $\dagger$ ) and electrochemical impedance spectroscopy (EIS) measurements were performed at an AC frequency of $10 \mathrm{kHz}$ in $1 \mathrm{M} \mathrm{NaOH}$ electrolyte solution using three-electrode electrochemical cells. As shown from the MottSchottky (M-S) plots in Fig. $1 \mathrm{~h}$ to 1 , both $\mathrm{MoS}_{2}$ and $\mathrm{MoS}_{2} / \mathrm{rGO}-$ PEG show a negative slope in the $\mathrm{M}-\mathrm{S} \operatorname{plot}\left(1 / C^{2} v s\right.$. potential (V), $C$ stands for capacitance) suggesting p-type character of the nanosheets whereas n-rGO shows a positive slope indicating n-type behaviour. With p-MoS $/$ n-rGO-PEG and p-MoS $/$ n-rGO$\mathrm{MnO}_{2}$-PEG nanosheets, the $\mathrm{M}-\mathrm{S}$ plots represent an inverted "V-shape" behaviour validating their $\mathrm{p}-\mathrm{n}$ heterojunction characteristics. ${ }^{\mathbf{8}, 13}$

The befitting optical properties of these nanosheets attest to their eligibility to act as a PDT agent, the most important being their absorption in the NIR region, $700-1100 \mathrm{~nm}$. At an equivalent concentration of $60 \mu \mathrm{g} \mathrm{mL}{ }^{-1}$, the initial observation from the optical absorbance spectra in Fig. 2a is the widening of absorbance from $\mathrm{GO}$ to $\mathrm{rGO}$ in the composite nanosheets, due to improved $\pi$-conjugation. Nitrogen doping in rGO further enhances the NIR absorbance because heteroatoms create more energy states which absorb lower energy photons. ${ }^{27}$ Dispersion of $\mathrm{MoS}_{2}$ nanoplates results in a weak absorption band at 610$670 \mathrm{~nm}$ whereas the decoration of $\mathrm{MnO}_{2} \mathrm{NPs}$ is evident from the weak absorption peak at $410 \mathrm{~nm}$. The other condition to become an efficient PDT agent is the ability to generate ROS namely ${ }^{1} \mathrm{O}_{2}$ under NIR light irradiation. With $980 \mathrm{~nm}$ light excitation, the ${ }^{1} \mathrm{O}_{2}$ phosphorescence quantum yield $(\Phi)$ of p- $\mathrm{MoS}_{2} / \mathrm{n}-\mathrm{rGO}-\mathrm{MnO}_{2}-\mathrm{PEG}$ was calculated to be $37 \%$ in acetonitrile $\left(\mathrm{CH}_{3} \mathrm{CN}\right)-\mathrm{D}_{2} \mathrm{O}$ solvent with respect to Rose Bengal (RB, $\Phi=0.76$ ) as a reference photosensitizer. ${ }^{28}$ The broad peak near $1271 \mathrm{~nm}$ due to radiative decay of ${ }^{1} \mathrm{O}_{2}{ }^{29}$ remains unaltered irrespective of $\mathrm{MnO}_{2} \mathrm{NP}$ decoration (Fig. 2b). ${ }^{1} \mathrm{O}_{2}$ can be monitored from its absorption by a trapping probe, 1,3-diphenylisobenzofuran (DPBF), which upon absorption degrades to an endoperoxide product via a Diels-Alder 1,4-cycloaddition process $^{30}$ that decreases the absorption intensity of DPBF. While NIR irradiation alone cannot produce ${ }^{1} \mathrm{O}_{2}$, which keeps the absorption intensity of DPBF at $410 \mathrm{~nm}$ unchanged (Fig. 2c,
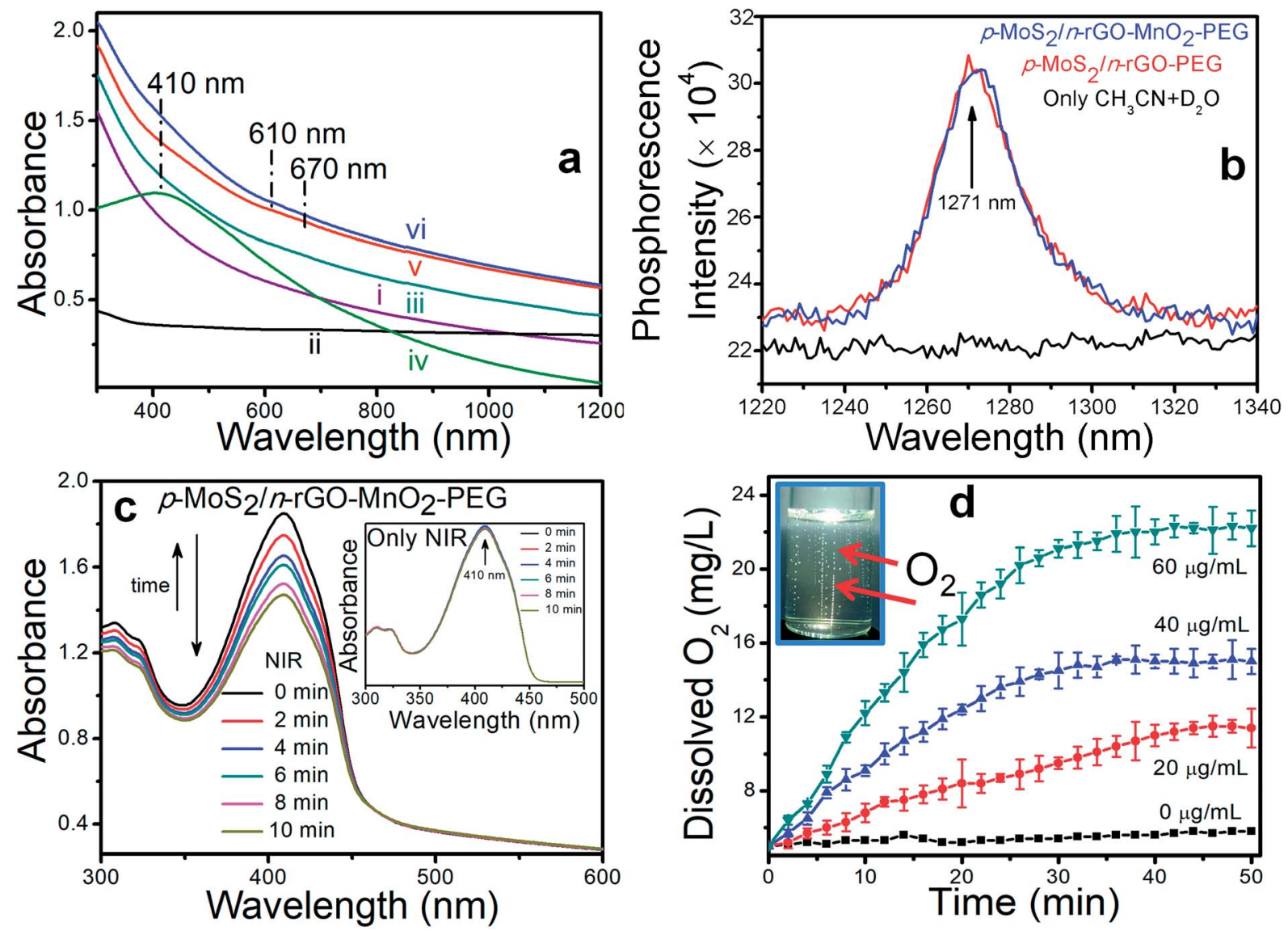

Fig. 2 (a) UV-vis-NIR spectra of the nanosheets: (i) GO, (ii) $\mathrm{MoS}_{2}$, (iii) $\mathrm{MoS}_{2} / \mathrm{rGO}-\mathrm{PEG}$, (iv) $\mathrm{MnO}_{2}$, (v) p-MoS $/ \mathrm{n}-\mathrm{rGO}-\mathrm{PEG}$, and (vi) p-MoS $/$ /n$\mathrm{rGO}-\mathrm{MnO}_{2}-\mathrm{PEG}$. (b) Singlet oxygen phosphorescence spectra sensitized by the nanosheets in the presence of $980 \mathrm{~nm}$ laser irradiation. (c) Time-dependent absorption spectra of DPBF in the presence of $\mathrm{p}-\mathrm{MoS}_{2} / \mathrm{n}-\mathrm{rGO}-\mathrm{MnO}_{2}-\mathrm{PEG}$ under laser irradiation. The inset shows the absorbance of DPBF in the presence of laser irradiation only. (d) The changes in $\mathrm{O}_{2}$ concentration with different concentrations of $\mathrm{p}-\mathrm{MoS} / \mathrm{n}$ $\mathrm{rGO}-\mathrm{MnO}_{2}-\mathrm{PEG}$ nanosheets in $100 \mu \mathrm{M} \mathrm{H}_{2} \mathrm{O}_{2}$ solutions. Data are represented as mean values $( \pm)$ standard deviations $(n=4)$. The inset shows the digital image of $\mathrm{O}_{2}$ bubble generation. 
inset), $\quad \mathrm{p}-\mathrm{MoS}_{2} / \mathrm{n}-\mathrm{rGO}-\mathrm{MnO}_{2}-\mathrm{PEG}$ nanosheets gradually decrease the absorption intensity with prolonged laser irradiation confirming the continuous generation of ${ }^{1} \mathrm{O}_{2}$ (Fig. 2c). When $\mathrm{H}_{2} \mathrm{O}_{2}$ is added to the medium under NIR irradiation, the higher $\mathrm{O}_{2}$ generation from $\mathrm{H}_{2} \mathrm{O}_{2}$ decomposition leads to more ${ }^{1} \mathrm{O}_{2}$ production which decreases the DPBF absorbance (Fig. S7 $\dagger$ ). Adding $\mathrm{NaN}_{3}$ as a radical scavenger removes the produced ROS, keeping the DPBF absorbance unchanged. ROS generation is further evaluated from the hydrolysis of nonfluorescent dye $2^{\prime}, 7^{\prime}$-dichlorofluorescein diacetate (DCFH-DA) to the fluorescent $2^{\prime}, 7^{\prime}$-dichlorofluorescein (DCF) via deacetylation reaction. ${ }^{30,31}$ Under NIR irradiation at $980 \mathrm{~nm}$, the DCF fluorescence intensity at $522 \mathrm{~nm}$ increases 19 fold with p-MoS$/$ n-rGO-MnO ${ }_{2}$-PEG as compared to $\mathrm{MoS}_{2} / \mathrm{rGO}-\mathrm{PEG}$ nanosheets (Fig. S7 $\dagger$ ), suggesting an effective ROS production. Since the concentration range of endogenous $\mathrm{H}_{2} \mathrm{O}_{2}$ in most tumour tissues is $10-100 \mu \mathrm{M}$, the dissolved oxygen (DO) production by p- $\mathrm{MoS}_{2} / \mathrm{n}-\mathrm{rGO}-\mathrm{MnO}_{2}-\mathrm{PEG}$ nanosheets in $100 \mu \mathrm{M} \mathrm{H}_{2} \mathrm{O}_{2}$ solution was measured with a portable DO meter (Fig. 2d). Since $\mathrm{MnO}_{2}$ NPs can catalytically trigger the decomposition of intracellular $\mathrm{H}_{2} \mathrm{O}_{2}$ to $\mathrm{O}_{2}$ and $\mathrm{H}_{2} \mathrm{O}$, upon adding different concentrations of the nanosheets, oxygen is produced rapidly (Fig. $2 \mathrm{~d}$ inset); thus DO increases proportionally with nanosheet concentration. In order to simulate a cellular hypoxic environment, the oxygen generating properties of these nanosheets were also evaluated in $\mathrm{N}_{2}$ saturated solutions at different $\mathrm{pH}$ (Fig. S8a and $\mathrm{b}^{\dagger}$ ). Among these nanosheets, $\mathrm{p}-\mathrm{MoS}_{2} / \mathrm{n}-\mathrm{rGO}-\mathrm{MnO}_{2}-\mathrm{PEG}$ efficiently generates enough oxygen that could alleviate the hypoxia conditions inside tumour tissues. With $20 \mu \mathrm{g} \mathrm{mL}{ }^{-1} \mathrm{p}-\mathrm{MoS}_{2} / \mathrm{n}$ rGO- $\mathrm{MnO}_{2}$-PEG nanosheets, the amount of dissolved $\mathrm{O}_{2}$ is $6.4 \mathrm{mg} \mathrm{L}^{-1}$ under normoxic conditions (Fig. 2d) as compared to $4.9 \mathrm{mg} \mathrm{L}^{-1}$ when the solution is saturated with $\mathrm{N}_{2}$ (Fig. S8a†). The $\mathrm{O}_{2}$ generation triggered by $\mathrm{p}-\mathrm{MoS}_{2} / \mathrm{n}-\mathrm{rGO}-\mathrm{MnO}_{2}-\mathrm{PEG}$ is faster at $\mathrm{pH} 5.5$ than at $\mathrm{pH} 7.4$ (Fig. S8b $\dagger$ ) since in an acidic environment, $\mathrm{MnO}_{2}$ can better react with $\mathrm{H}_{2} \mathrm{O}_{2}$.

\section{In vitro cytotoxicity and PDT}

In the absence of NIR illumination, all the nanosheets starting from $\mathrm{rGO}$ and $\mathrm{MoS}_{2} / \mathrm{rGO}-\mathrm{PEG}$ to $\mathrm{p}-\mathrm{MoS}_{2} / \mathrm{n}$-rGO-PEG and $\mathrm{p}$ $\mathrm{MoS}_{2} / \mathrm{n}$-rGO- $\mathrm{MnO}_{2}-\mathrm{PEG}$ at different concentrations $(25,50$, $100,200 \mu \mathrm{g} \mathrm{mL} \mathrm{m}^{-1}$ ) demonstrate excellent cell viability for $48 \mathrm{~h}$ both with HeLa cells (human cervical carcinoma cells) and HEK 293 cells (human embryo kidney cells) as shown by standard methyl thiazolyl tetrazolium (MTT) assay, ${ }^{32}$ in Fig. 3a and S9. $\dagger$ Specifically, the cell viability at a high concentration of $200 \mu \mathrm{g}$ $\mathrm{mL}^{-1} \mathrm{p}-\mathrm{MoS}_{2} / \mathrm{n}-\mathrm{rGO}-\mathrm{MnO}_{2}-\mathrm{PEG}$ nanosheets is $\sim 85 \%$ against both HeLa and HEK 293 cells. An efficient PDT agent should exhibit notable cytotoxicity towards cancer cells only under light irradiation whereas in the absence of light it is supposed to be benign in all types of cells. When HeLa cells are incubated for $12 \mathrm{~h}$ with $60 \mu \mathrm{g} \mathrm{mL}{ }^{-1} \mathrm{p}-\mathrm{MoS}_{2} / \mathrm{n}$-rGO- $\mathrm{MnO}_{2}-\mathrm{PEG}$ nanosheets accompanied by $980 \mathrm{~nm}$ NIR laser irradiation $\left(0.4 \mathrm{~W} \mathrm{~cm}^{-2}, 5\right.$ min), cell viability reduces to $30 \%$ after $24 \mathrm{~h}$ incubation (Fig. S10†). The cell viability reduces further to $14 \%$ at $120 \mu \mathrm{g}$ $\mathrm{mL}^{-1}$, which is a usual occurrence with increasing concentration of the PDT agents. The presence of $\mathrm{MnO}_{2}$ NPs helps to overcome tumour hypoxia, ${ }^{10}$ such that at $120 \mu \mathrm{g} \mathrm{mL}{ }^{-1}$ concentration, the in vitro cell killing efficacy is 3-fold and more than 5fold as compared to that of $\mathrm{MoS}_{2} / \mathrm{rGO}-\mathrm{PEG}$ and $\mathrm{p}-\mathrm{MoS}_{2} / \mathrm{n}-\mathrm{rGO}-$ PEG, respectively. Cell killing can be further enhanced by increasing the laser power density (Fig. S11†). However since the threshold temperature for cell apoptosis is about $43{ }^{\circ} \mathrm{C},{ }^{29}$ temperature elevation was controlled to less than $40{ }^{\circ} \mathrm{C}$ by tuning the concentration, limiting the laser power density and irradiation time in order to minimize the photothermal effect and maximize the PDT effect. Accordingly, the nanosheet concentration was fixed at $60 \mu \mathrm{g} \mathrm{mL} \mathrm{m}^{-1}$ with 5 min laser irradiation at $0.4 \mathrm{~W} \mathrm{~cm}^{-2}$ power density (Fig. $3 \mathrm{~b}$ ) where the cell killing efficiency of $\mathrm{p}-\mathrm{MoS}_{2} / \mathrm{n}-\mathrm{rGO}-\mathrm{MnO}_{2}-\mathrm{PEG}$ is still 3.3 and 2.5 times higher than that of $\mathrm{MoS}_{2} / \mathrm{rGO}-\mathrm{PEG}$ and $\mathrm{p}-\mathrm{MoS}_{2} / \mathrm{n}$-rGO-PEG, respectively. However a mild photothermal effect can increase the efficiency of nanosheet uptake by the cells, ${ }^{33}$ as well as enhancing the photocatalysis process through improved mobility of photogenerated charge carriers. ${ }^{34}$ When a ${ }^{1} \mathrm{O}_{2}$ quencher such as $50 \mu \mathrm{M} \mathrm{NaN}{ }_{3}$ is added, cell viability shows an improving trend even in the presence of laser irradiation, highlighting the importance of ${ }^{1} \mathrm{O}_{2}$ induced oxidative damage for cancer cell death. ${ }^{35}$

The promising therapeutic PDT efficacy of these nanosheets was evaluated by monitoring the fluorescence microscope images obtained by co-staining with fluorescein diacetate for live cells and propidium iodide (PI) for dead cells (Fig. 3c and S12 $\dagger$ ). Without NIR irradiation the cells are not visibly damaged by the biocompatible nanosheets as evident from the vivid green fluorescence. With NIR irradiation the merged fluorescence images show a substantial increase in red fluorescence. From the fluorescence microscopy images of 1500 cells it is observed that more than $90 \%$ of the cells are damaged by p$\mathrm{MoS}_{2} / \mathrm{n}$-rGO- $\mathrm{MnO}_{2}$-PEG as compared to $\sim 25 \%$ and $\sim 8 \%$ damaged cells for $\mathrm{p}-\mathrm{MoS}_{2} / \mathrm{n}$-rGO-PEG and $\mathrm{MoS}_{2} / \mathrm{rGO}-\mathrm{PEG}$, respectively. Furthermore, the intracellular ROS production was investigated by fluorescence microscopy with cell permeable green fluorescent ROS indicator DCFDA. As observed in Fig. 3d, both NIR irradiation and the $\mathrm{p}-\mathrm{n}$ heterojunction nanosheets are required to increase the intracellular ROS yield in HeLa cells by intracellular electron-hole pair separation. A remarkable green fluorescence of DCF is observed with p-MoS $2 / \mathrm{n}-\mathrm{rGO}-\mathrm{MnO}_{2}-\mathrm{PEG}$ and $\mathrm{p}-\mathrm{MoS}_{2} / \mathrm{n}$-rGO-PEG whereas the green fluorescence is negligible for control cells and $\mathrm{MoS}_{2} / \mathrm{rGO}-\mathrm{PEG}$. Obviously, upon adding the $\mathrm{NaN}_{3}$ scavenger the fluorescence intensity decreases. Flow cytometry reveals a remarkable shift in the DCF fluorescence intensity (Fig. 3d(E)) wherein the quantified fluorescence intensities of DCF with NIR treated p- $\mathrm{MoS}_{2} / \mathrm{n}$-rGO-MnO ${ }_{2}-\mathrm{PEG}$, p-MoS $/$ n-rGO-PEG, and $\mathrm{MoS}_{2} / \mathrm{rGO}-\mathrm{PEG}$ nanosheets are 14, 8, and 3 -fold more as compared to only NIR treated samples, respectively.

To understand the mechanistic cell death either by apoptotic or necrotic pathways, flow cytometry was employed with an Alexa Fluor 488 Annexin V/dead cell apoptosis kit. The involvement of dual staining, green emission from Alexa Fluor 488-Annexin V, affinity to bind phosphatidyl serine and DNA binding PI dye with red emission combine to identify the cellular apoptotic (early or late) or necrotic pathways. During the early stage of apoptosis, 

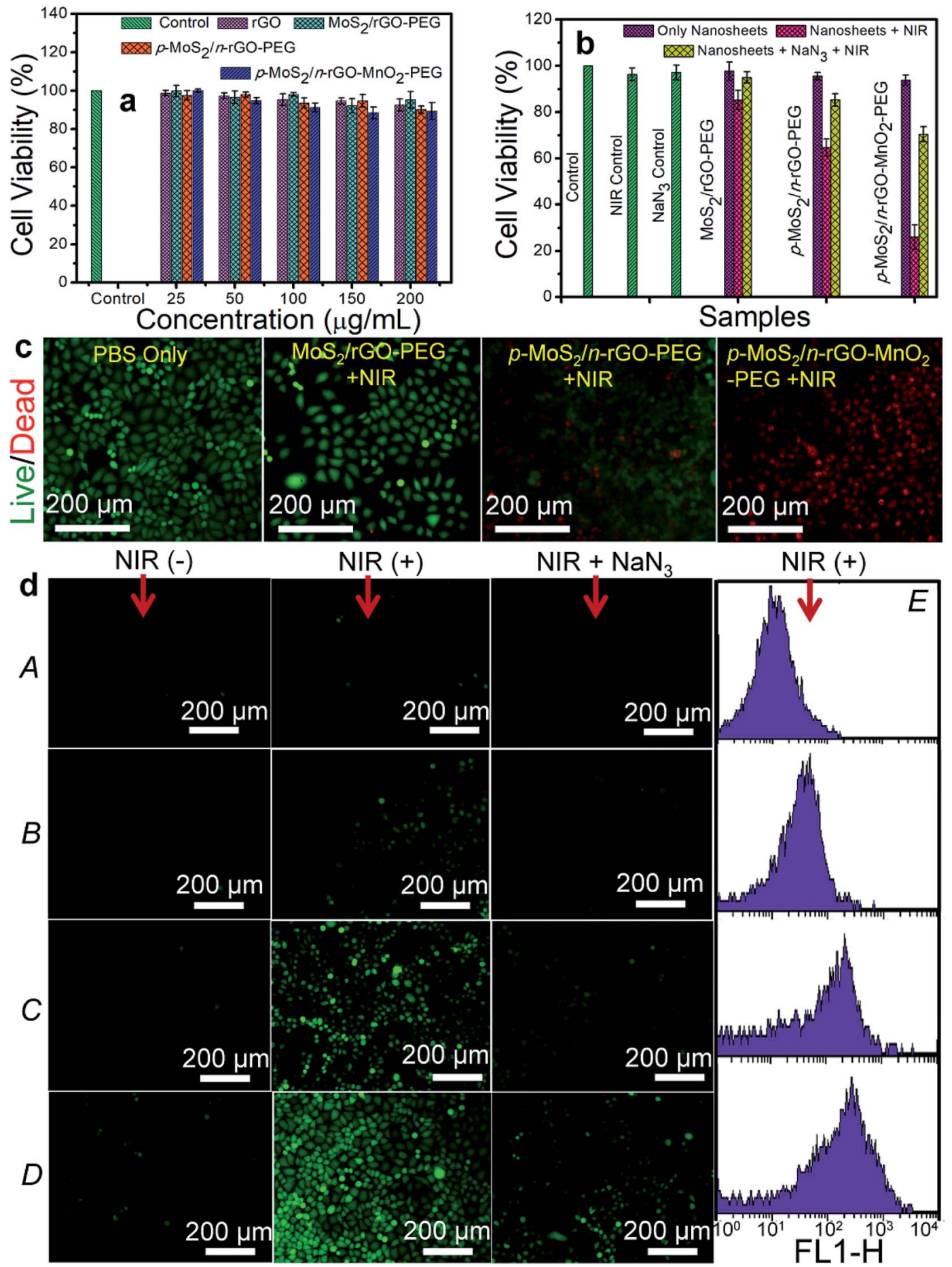

Fig. 3 (a) Cell viability of HeLa cells incubated with different concentrations of the nanosheets for $48 \mathrm{~h}$. (b) Cell viability of HeLa cells incubated with $\mathrm{MoS}_{2} / \mathrm{rGO}-\mathrm{PEG}, \mathrm{p}-\mathrm{MoS}_{2} / \mathrm{n}-\mathrm{rGO}-\mathrm{PEG}$ and p-MoS $/ \mathrm{n}-\mathrm{rGO}-\mathrm{MnO}_{2}-\mathrm{PEG}$ at a fixed concentration of $60 \mu \mathrm{g} \mathrm{mL} \mathrm{L}^{-1}$ in the presence or absence of $0.4 \mathrm{~W} \mathrm{~cm}^{-2}$ laser irradiation for $5 \mathrm{~min}$. In (a) and (b), data are represented as mean values ( \pm ) standard deviations $(n=3)$. (c) Merged epifluorescence microscopy images of HeLa cells co-stained with fluorescein diacetate (green emission for live cells) and PI (red emission for dead cells) under $0.4 \mathrm{~W} \mathrm{~cm}^{-2}$ laser irradiation for $5 \mathrm{~min}$. (d) Epifluorescence microscopy images of HeLa cells under different treatments: (A) incubated with only DCFH-DA, (B) incubated with DCFH-DA + MoS $_{2} / r G O-P E G,(C)$ incubated with DCFH-DA + p-MoS $/ 2$ - $r G O-P E G$, and (D) incubated with $\mathrm{DCFH}-\mathrm{DA}+\mathrm{p}-\mathrm{MoS}_{2} / \mathrm{n}-\mathrm{rGO}-\mathrm{MnO}_{2}-\mathrm{PEG}$, in the presence or absence of $\mathrm{NaN}_{3}$ and NIR irradiation for 5 min. (E) Flow cytometry analysis of NIR irradiation triggered ROS incubated with DCFH-DA in the presence or absence of the nanosheets.

cells bind to Alexa Fluor 488-Annexin V and change their phospholipid asymmetry to display green fluorescence while necrotic cells bind only with PI. In late apoptosis the cells lose their membrane integrity and display dual positive emission. Under NIR irradiation for $5 \mathrm{~min}$, the population of apoptotic and dead cells for $\mathrm{p}-\mathrm{MoS}_{2} / \mathrm{n}$-rGO-MnO ${ }_{2}-\mathrm{PEG}$ is $\sim 90 \%$, much higher than 


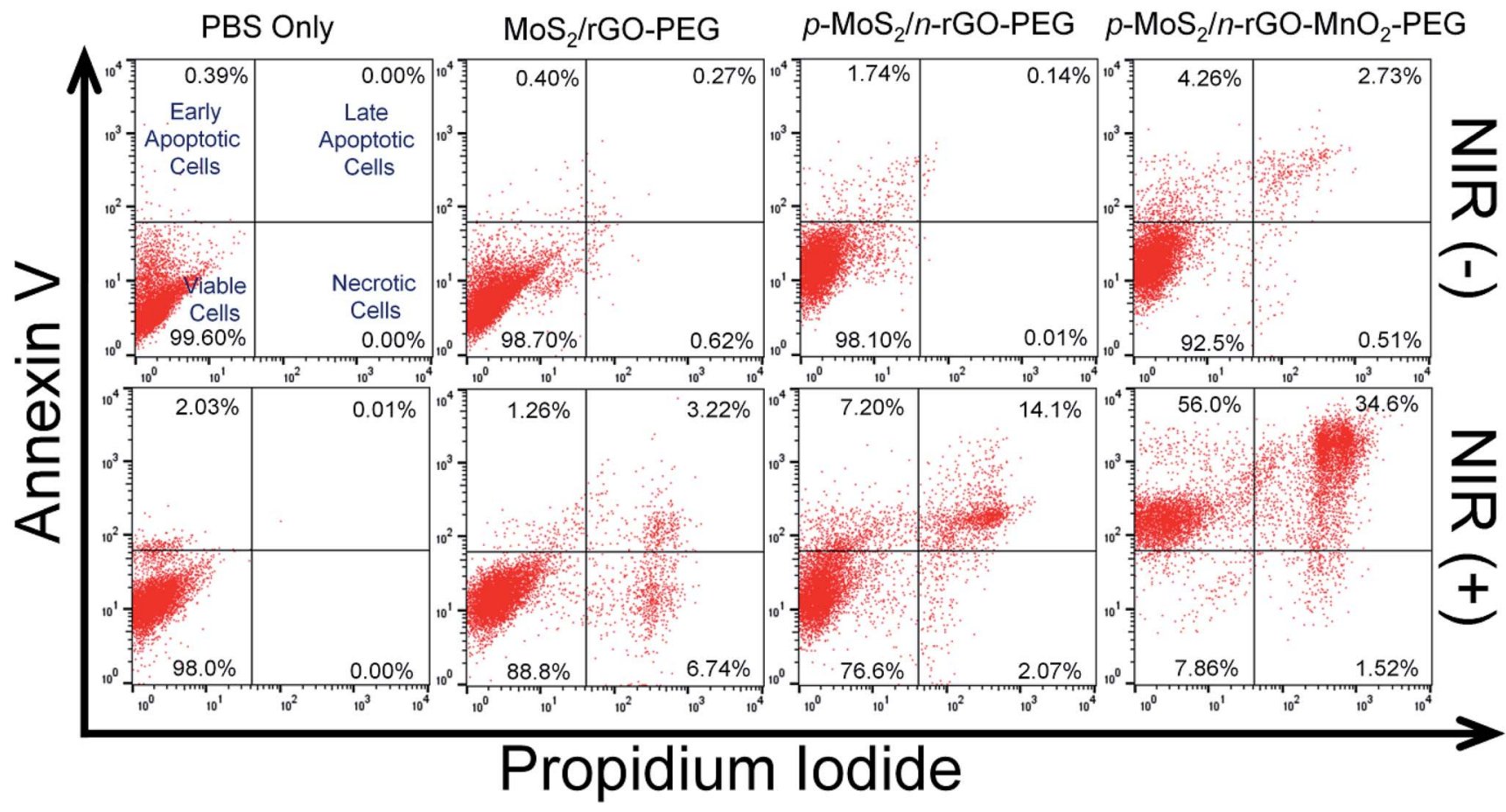

Fig. 4 Flow cytometry analysis of HeLa cells in the presence of different formulations with or without NIR irradiation. In the case of early apoptosis (top left), Annexin V-Alexa Fluor 488 is positive and PI is negative. For late apoptosis (top right), both are positive. The dead cells (bottom right) have negative Annexin V-Alexa Fluor 488 and positive PI whereas in the case of live cells (bottom left) both are negative.

$\sim 21 \%$ for $\mathrm{p}-\mathrm{MoS}_{2} / \mathrm{n}$-rGO-PEG and $\sim 5 \%$ for $\mathrm{MoS}_{2} / \mathrm{rGO}-\mathrm{PEG}$ (Fig. 4). The minimal cell population in the necrosis stage suggests that the decrease in cell membrane integrity occurs via an apoptosis pathway. The statistical data of cell population at various stages of cellular damage validate the effectiveness of $\mathrm{p}$ $\mathrm{MoS}_{2} / \mathrm{n}$-rGO-MnO ${ }_{2}$-PEG nanosheets in producing ROS in HeLa cells activated by intracellular $\mathrm{H}_{2} \mathrm{O}_{2}$ and NIR irradiation. Most importantly these $\mathrm{p}-\mathrm{n}$ heterojunction nanosheets act as active photosensitizers wherein the charge carriers can be separated and along with the advantage of $\mathrm{MnO}_{2} \mathrm{NPs}$ in producing intracellular ROS, together make this system an exceptional PDT agent, as demonstrated in vitro.

Notwithstanding the unprecedented efficacy of $\mathrm{p}-\mathrm{n}$ heterojunction nanosheets towards PDT, demonstrated in vitro, there are complexities that abound within the biomicroenvironment of animal systems, primarily associated with the dynamic nonspecific interactions between the nanostructures and biological entities. Starting from in vivo cellular internalization to bioclearance, the complicacies associated with the designed PDT agent involve their size, shape, agglomeration, dissolution, doses, protein adsorption, biodegradation, surface reactivity and macrophage uptake. ${ }^{36}$ At the foremost, precise nanosheet doses are required to prevent heart blockage. Moreover due to formation of a protein corona complex, the nanosheets might be engulfed by macrophage cells. Also bioclearance of the nanosheets through excretion and biodegradation processes will depend on the appropriate nanosheet dimensions and surface chemistry wherein rapid clearance may lead to overaccumulation in non-targeted organs. Taking these perplexities into account, the in vivo experiments will be the topic of our future study in order to evaluate the toxicity, biodistribution, body clearance and mechanistic PDT efficacy of $\mathrm{p}-\mathrm{n}$ heterojunction nanosheets in the native biomicroenvironment.

\section{Conclusions}

In summary, we successfully designed a unique twodimensional hybrid nanoplatform based on PEGylation of $\mathrm{MnO}_{2}$ decorated $\mathrm{p}-\mathrm{MoS}_{2} / \mathrm{n}$-rGO heterojunction nanosheets (p-Mos ${ }_{2} / \mathrm{n}$-rGO-MnO $\left.{ }_{2}-\mathrm{PEG}\right)$. These hybrid nanosheets show unprecedented performance as an $\mathrm{O}_{2}$ self-sufficient NIR lighttriggered PDT agent. The as-synthesized nanosheets retain their excellent colloidal stability in water, phosphate buffered saline with different $\mathrm{pH}$ and in biological media. While the $\mathrm{p}-\mathrm{n}$ heterojunction directs NIR light triggered generation and separation of electron-hole pairs that could increase the production of ROS via photocatalysis, $\mathrm{MnO}_{2}$ NPs increase intracellular $\mathrm{O}_{2}$ by the reaction with endogenous $\mathrm{H}_{2} \mathrm{O}_{2}$ to overcome the hypoxic conditions in the cellular microenvironment. Compared to p-MoS $2 /$ n-rGO-PEG and $\mathrm{MoS}_{2} /$ rGO-PEG, the $\mathrm{p}-\mathrm{MoS}_{2} / \mathrm{n}$-rGO- $\mathrm{MnO}_{2}-\mathrm{PEG}$ nanosheets show enhanced DCF fluorescence and reveal hypoxia induced increased apoptosis under NIR light irradiation. Since the $\mathrm{p}-\mathrm{MoS}_{2} / \mathrm{n}-\mathrm{rGO}-\mathrm{MnO}_{2}-$ PEG nanosheets have been demonstrated in vitro to be an efficient PDT photosensitizer for cancer therapy, our strategy can be applied in developing other nanoscale heterojunction materials for biomedical applications. 


\section{Conflicts of interest}

There are no conflicts to declare.

\section{Acknowledgements}

The authors thank Dr Sankar Maiti for providing the cell culture facilities, and Arikta Biswas and Dr Bidisha Sinha for fluorescence microscopy imaging under the Wellcome Trust/DBT India Alliance fellowship (grant number IA/I/13/1/500885) awarded to Dr Sinha. The Department of Science and Technology-Science and Engineering Board (DST-SERB), Government of India is duly acknowledged for the financial support under grant no. EMR/2016/001703. S. K. thanks the Council of Scientific and Industrial Research (CSIR), New Delhi for his fellowship (award number 09/921 (0089)/2013EMR-I). The authors acknowledge Dr M. Venkataramanan for providing access to the laser setup. S. K. acknowledges the help of Atharva Sahasrabudhe for impedance spectroscopy measurements and discussions, and Rahul Majee for STEMHAADF imaging.

\section{References}

1 J. T. Calow, P. J. Deasley, S. J. T. Owen and P. W. Webb, J. Mater. Sci., 1967, 2, 88-96.

2 P. J. Jeon, Y. T. Lee, J. Y. Lim, J. S. Kim, D. K. Hwang and S. Im, Nano Lett., 2016, 16, 1293-1298.

3 M.-L. Tsai, M.-Y. Li, J. R. D. Retamal, K.-T. Lam, Y.-C. Lin, K. Suenaga, L.-J. Chen, G. Liang, L.-J. Li and J.-H. He, Adv. Mater., 2017, 29, 1701168.

4 D. Saxena, N. Jiang, X. Yuan, S. Mokkapati, Y. Guo, H. H. Tan and C. Jagadish, Nano Lett., 2016, 16, 5080-5086.

5 J. Hu, Y. Tang, A. H. Elmenoufy, H. Xu, Z. Cheng and X. Yang, Small, 2015, 11, 5860-5887.

6 A. P. Castano, P. Mroz and M. R. Hamblin, Nat. Rev. Cancer, 2006, 6, 535-545.

7 D. E. J. G. J. Dolmans, D. Fukumura and R. K. Jain, Nat. Rev. Cancer, 2003, 3, 380.

8 F. Meng, J. Li, S. K. Cushing, M. Zhi and N. Wu, J. Am. Chem. Soc., 2013, 135, 10286-10289.

9 Y. Chang, Y. Cheng, Y. Feng, H. Jian, L. Wang, X. Ma, X. Li and H. Zhang, Nano Lett., 2018, 2, 886-897.

10 Z. Guo, S. Zhu, Y. Yong, X. Zhang, X. H. Dong, J. F. Du, J. N. Xie, Q. Wang, Z. J. Gu and Y. L. Zhao, Adv. Mater., 2017, 29(1-12), 1704136.

11 R. Parameswaran, J. L. Carvalho-de-Souza, Y. Jiang, M. J. Burke, J. F. Zimmerman, K. Koehler, A. W. Phillips, J. Yi, E. J. Adams, F. Bezanilla and B. Tian, Nat. Nanotechnol., 2018, 13, 260-266.

12 D. Chimene, D. L. Alge and A. K. Gaharwar, Adv. Mater., 2015, 27, 7261-7284.
13 K. Zhang, W. J. Kim, M. Ma, X. J. Shi and J. H. Park, J. Mater. Chem. A, 2015, 3, 4803-4810.

14 J. Kim, H. R. Cho, H. Jeon, D. Kim, C. Song, N. Lee, S. H. Choi and T. Hyeon, J. Am. Chem. Soc., 2017, 139, 10992-10995.

15 W. Zhang, S. Li, X. Liu, C. Yang, N. Hu, L. Dou, B. Zhao, Q. Zhang, Y. Suo and J. Wang, Adv. Funct. Mater., 2018, (19), 1706375.

16 G. Yang, L. Xu, Y. Chao, J. Xu, X. Sun, Y. Wu, R. Peng and Z. Liu, Nat. Commun., 2017, 8, 902.

17 J. Liu, Q. Chen, W. Zhu, X. Yi, Y. Yang, Z. Dong and Z. Liu, Adv. Funct. Mater., 2017, 27, 1605926.

18 L. Cheng, C. Wang, L. Feng, K. Yang and Z. Liu, Chem. Rev., 2014, 114, 10869-10939.

19 K. Susumu, B. C. Mei and H. Mattoussi, Nat. Protoc., 2009, 4, 424.

20 B. Debnath, A. S. Roy, S. Kapri and S. Bhattacharyya, ChemistrySelect, 2016, 1, 4265-4273.

21 A. Datta, S. Kapri and S. Bhattacharyya, Green Chem., 2015, 17, 1572-1580.

22 D. Ghosh, G. Halder, A. Sahasrabudhe and S. Bhattacharyya, Nanoscale, 2016, 8, 10632-10641.

23 K. Moon, J. Lee, R. S. Ruoff and H. Lee, Nat. Commun., 2010, $1,73$.

24 T. Jiang, L. Zhang, H. Jin, X. Wanga and J. Zhou, Dalton Trans., 2015, 44, 7606-7612.

25 D. H. Youn, J.-W. Jang, J. Y. Kim, J. S. Jang, S. H. Choi and J. S. Lee, Sci. Rep., 2014, 4, 5492.

26 A. Sahasrabudhe, S. Kapri and S. Bhattacharyya, Carbon, 2016, 107, 395-404.

27 C. Lee, W. Kwon, S. Beack, D. Lee, Y. Park, H. Kim, S. K. Hahn, S. W. Rhee and C. Kim, Theranostics, 2016, 6, 2196-2208.

28 J. Ge, M. Lan, B. Zhou, W. Liu, L. Guo, H. Wang, Q. Jia, G. Niu, X. Huang, H. Zhou, X. Meng, P. Wang, C.-S. Lee, W. Zhang and X. Han, Nat. Commun., 2014, 5, 4596.

29 P. Kalluru, R. Vankayala, C. S. Chiang and K. C. Hwang, Biomaterials, 2016, 95, 1-10.

30 H. Wang, X. Yang, W. Shao, S. Chen, J. Xie, X. Zhang, J. Wang and Y. Xie, J. Am. Chem. Soc., 2015, 137, 11376-11382.

31 H. J. Zhu, J. C. Li, X. Y. Qi, P. Chen and K. Y. Pu, Nano Lett., 2018, 18, 586-594.

32 S. Kapri, S. Maiti and S. Bhattacharyya, Carbon, 2016, 100, 223-235.

33 J. Wei, J. Li, D. Sun, Q. Li, J. Ma, X. Chen, X. Zhu and N. Zheng, Adv. Funct. Mater., 2018, 1706310.

34 Z. X. Gan, X. L. Wu, M. Meng, X. B. Zhu, L. Yang and P. K. Chu, ACS Nano, 2014, 8, 9304.

35 L. Huang, Z. Li, Y. Zhao, Y. Zhang, S. Wu, J. Zhao and G. Han, J. Am. Chem. Soc., 2016, 138, 14586-14591.

36 B. Wang, X. He, Z. Zhang, Y. Zhao and W. Feng, Acc. Chem. Res., 2013, 46, 761-769. 